\title{
Activation of the cognitive activity of students of a technical university through the individualization of education
}

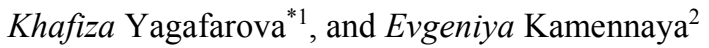 \\ ${ }^{1}$ Ufa State Petroleum Technological University, Branch of the University in the City of Oktyabrsky, 54a, Devonskaya St., \\ Oktyabrsky, Republic of Bashkortostan, 452607, Russia \\ ${ }^{2}$ SBVEI Oktyabrsky Petroleum College named after S.I. Kuvykin, 15 Kuvykina St., Oktyabrsky, Republic of Bashkortostan, \\ 452607, Russia
}

\begin{abstract}
To adapt to work activity, find a creative approach to changes in the job market, it is necessary to have high-quality training of a technical university graduate. This article presents possible ways to solve problems of identifying overt and hidden talents, extraordinary abilities and creative thinking of students. Particular attention is paid to the consideration of the motivating aspects of the cognitive activity of students through the individualization of education in the modern educational system of the higher technical university. The data on the participation of students of the Branch of the Ufa State Petroleum Technological University in the city of Oktyabrsky in the Open International Student Disciplinary Internet Olympiads are given. The issues of enhancing students' cognitive activity through the identification of individual intellectual abilities of each student are covered. The analysis of the results of Internet Olympiads for the period from 2012 to 2018 in the disciplines of various cycles was carried out, changes in quantitative and qualitative indicators in fifteen disciplines in the profile "Technique and Technology" were revealed, the possibilities of improving the efficiency of preparing students of higher educational institutions for scientific activities were shown.
\end{abstract}

\section{Introduction}

The modern Russian education system is formed in the new socio-economic conditions that cause changes in the requirements for graduates of higher educational institutions. Qualitative training of an engineer is inextricably linked with the need to develop clear requirements for the general cultural and professional competencies of graduates of technical universities, which would allow them to quickly adapt to work activities, to creatively approach any changes in the job market. Therefore, a higher technical school is faced with a task that would shape the conditions for enhancing students' cognitive activity and individualize the approach to students. This, in turn, will bring up an active, enterprising, independent professional, striving to improve their cultural and professional level, and eventually form the system engineering thinking of the future specialist. In this case, the organization of the educational process, taking into account the individual characteristics of students, allows you to create optimal conditions for the realization of the potential opportunities of each student [1].

At present, significant aspects of the problem of the individualization of learning are analyzed in the scientific works of E.L. Huseynova, in whose opinion individualization is realized not in the whole volume of educational activity, but occasionally, or in some kind of educational work and integrated with non-individualized work [1]. An important aspect in the individualization of the learning process is the Olympiads that stimulate the development of new methods, means and forms of learning and intellectual development of students. In the context of the formation of general cultural and professional competences, holding student competitions is a powerful incentive for enhancing cognitive activity and motivation for the learning process of students of the Ufa State Petroleum Technological University (USPTU) branch in the city of Oktyabrsky [2].

In scientific works by Shangareev R.R. claims that due to the education modernization, changes in the field of industrial technologies necessitate the formation of a specialist "special, super-professional, or rather extrafunctional knowledge and skills, properties, qualities and abilities that ensure his professional mobility, competitiveness and social security" [3]. At the same time, Huseynova E.L. believes that: "In the process of the formation of professional skill, two stages can be distinguished - university and postgraduate. At the university stage, the professional development of specialists is ensured through the development of their cognitive activity and the formation of professional training. The post-graduate stage is characterized by independent professional activity, in the course of which the specialist's professional skills develop to the highest

* Corresponding author: Yagafarova-kh@mail.ru 
level of professionalism, the basis for which is his cognitive activity-activated during the period of professional training at the university. Cognitive activity influences the formation of the personality of the student, his attitude towards himself, other people, and production" [1].

\section{Methods and Methodology}

The faculty are faced with the task of creating pedagogical conditions that would stimulate and intensify the educational activities of students. The solution to this problem is the didactic principle, providing for an individual approach at the subjective level. The implementation of an individual approach involves the targeted construction of the educational process. An individual approach to learners allows you to form an active, enterprising, independent professional seeking to improve their cultural and professional level. The implementation of the modernization of education in the system of higher education in order to improve the quality of technical specialists training is one of the most relevant in the theory and methodology of higher education [4].

Modern trends in the development of professional technical training are developing in the context of the transition to an information society. In modern society, new areas of young specialist training are developing in the conditions of transition from industrial society to the level of information and communication networks, which is closely linked to the development of the process of informatization of society and the use of information technologies, and the development of educational systems in the process of creating and disseminating knowledge takes place.

As a result of the activation of cognitive activity, the level of development of intellectual abilities increases, which allows the student to effectively solve new life and professional problems, especially of a global nature, that is: to be open with respect to the new; realistically approach emerging issues, see them in all complexity, inconsistency and diversity; have a broad and flexible mindset, see alternative solutions and overcome existing stereotypes; critically analyze experience, be able to learn from the past [5].

Of course, a higher education institution provides certain professional knowledge and skills, the possibility of their practical application and obtaining an initial understanding of the job market in the form of practical placement. The university also provides educational loans listed on the labor market and confirmed by the reputation and name of the university: bachelor's degree, specialist degree, master's degree and certificates of obtaining scientific degrees. But its most important function is the development of the general cultural capital of students, which lays the universal foundation for further professional activity and subsequent development. Therefore, in the current conditions of the labor market, it is of great importance to analyze how the university stimulates, or, on the contrary, hinders the increase in the level and quality of training of specialists.
One of the main tasks of modern higher education in the context of globalization and the integration of Russian education into the world educational space is the identification of talented, bright-minded and creative young people [6]. Conducting such creative scienceoriented events as the Olympiad contributes to the solution of this problem. The expansion of the application of modern information and communication technologies in the field of education allows mass participation of gifted students in competitions and expands the geography of participants. Conducting online Olympiads allows you to identify truly talented young people who are capable of scientific research related to market needs in the high-tech industries of the innovative economy of Russia [7].

The most effective way to enhance students' cognitive activity in the learning process and to solve this educational problem is to prepare for scientific research activities, which involves the participation of students not only in basic and applied research in the field of creating new technologies, but also their participation in competitions at various levels. Since student Olympiads set and implement the following goals:

- increasing the level and quality of education;

- formation of interest in the studied discipline and the development of skills of independent activity;

- education of the will to overcome difficulties, to search for non-standard ways of solving problems;

- popularization of knowledge and expansion of students;

- identifying the most talented students who know how to think extraordinarily, ensuring their future creative activity;

- a comparative assessment of the quality of education of students of different specialties and groups;

- material and moral support of talented youth, etc.

It is important that student disciplinary Internet Olympiads remain the most objective, indicative, and authoritative intellectual competition of students of higher educational institutions [8]. But invariably the main task of the mass stage of the Olympiad should not be a sample of students, but their maximum involvement in scientific research activities. At the same time, the results of student olympiads stimulate the development of new methods, means and forms of education, increasing the experience and erudition and pedagogical skills of the faculty of the higher educational institution. Undoubtedly, the fact that the tasks that are offered at the student competitions after their introduction into the system of the educational process of a higher educational institution introduce new elements into the program of the studied discipline. And thus, a rich and versatile material is accumulated, which greatly enriches the pedagogical experience, improves professional skills, and, consequently, improves the quality of training of specialists.

Student Olympiad is the motivation of students' cognitive activity [9], and a spirit of rivalry arises, bright intellectual individual features are manifested by posing non-standard and non-traditional questions and tasks at the Olympiads. The manifestation of the spirit of rivalry 
is reflected in the fact that each participant of the Olympiad wants to achieve the best results. For students of the Olympiad, it gives them the opportunity to believe in themselves, assert themselves, to gain confidence in their intellectual and creative abilities. If we talk about small achievements and indicators in Olympiads, then they give rise to a belief in a student in themselves and in their capabilities. This is the motivation for cognitive activity through the manifestation of their individual characteristics. Olympiads are an important aspect in identifying overt and hidden talents, extraordinary and creatively gifted students [10]. Important pedagogical conditions are the popularization of the scientific activity of students, in identifying the individuality and characteristics of each student, since it is important for students to create a system of conditions for the development of the individual as a whole and the specialist in particular. These conditions allow us to reveal the individuality of the student, his creative potential in the process of mastering the professional activity. Therefore, every year students of the branch of the USPTU in the city of Oktyabrsky take part in competitions at various levels in many disciplines, but we pay particular attention to the Open International Internet Olympiad (organized by the National Fund for Innovation Support in Education, the Scientific Research Institute for Monitoring Education).

Open international student Internet Olympiad on the "Technology and Technology" profile is conducted in fifteen disciplines of higher education in the humanities, socio-economic, natural science and general professional cycles. Sections of disciplines are determined in accordance with the requirements of the Federal State Educational Standards for Higher Education (FSES) of the Russian Federation.

The Open International Student Internet Olympiad has been held among students of the first three courses of higher education institutions using information and communication technologies (in the form of computer on-line testing) since 2008. In accordance with the regulations of the Organizing Committee of the Internet Olympiad is held in two rounds, with the exception of mathematics, according to which the Olympiad is held in three rounds (the third round - All-Russian, international). The first (qualifying) round of the Internet Olympiad is conducted by scientific adviser among students of an educational institution, and the second (regional) round is held at basic universities of the country. In the Republic of Bashkortostan, Ufa State Aviation Technical University was appointed as the base institution. According to the results of the first qualifying round, the three best students are invited to the second round of the Internet Olympiad. All participants of the second round will be awarded certificates, and the winners will be awarded gold, silver and bronze medals.

The participation of students of our Branch in all disciplines: mathematics, physics, chemistry, computer science, ecology, theoretical mechanics, strength of materials, Russian language, History of Russia, legal science, philosophy, economy, statistics for the last 7 years are summarized in the final table 1. According to table 1 compiled a chart of quantitative and qualitative changes in the results of the Internet Olympiad in the period from 2012 to 2018 (Fig. 1).

Table 1. Branch student participation statistics for the last 7 years

\begin{tabular}{|c|c|c|c|c|}
\hline $\begin{array}{c}\text { Calend } \\
\text { ar year }\end{array}$ & $\begin{array}{c}\text { Number } \\
\text { of } \\
\text { participa } \\
\text { nts } \\
\text { 1 round }\end{array}$ & $\begin{array}{c}\text { Annual } \\
\text { increme } \\
\text { nt, } \\
\mathbf{\%}\end{array}$ & $\begin{array}{c}\text { Numbe } \\
\text { r of } \\
\text { particip } \\
\text { ants } \\
\text { 2 round }\end{array}$ & $\begin{array}{c}\text { Annual } \\
\text { increme } \\
\text { nt, } \\
\%\end{array}$ \\
\hline 2012 & 83 & - & 21 & - \\
\hline 2013 & 109 & +31 & 24 & +14.3 \\
\hline 2014 & 177 & +62 & 25 & +4.2 \\
\hline 2015 & 208 & +17 & 27 & +8 \\
\hline 2016 & 161 & -29 & 29 & +7.4 \\
\hline 2017 & 147 & -9 & 26 & -11.5 \\
\hline 2018 & 274 & +86 & 31 & +19.2 \\
\hline
\end{tabular}

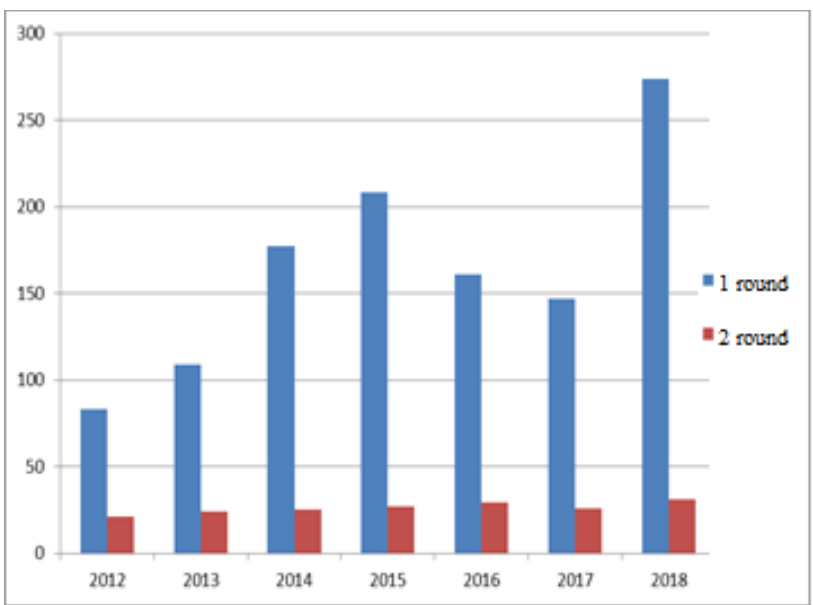

Fig. 1. Diagram of quantitative and qualitative changes from 2012 to 2018.

The results below show that the students and the faculty of the Branch are more and more actively participating in Internet Olympiads and these data are reflected on the main page of the website http://olymp.iexam.ru.

The active participation of students of our Branch at the Open International Student Internet Olympiads is annually marked by the Letters of gratitude to the Organizing Committee of the Internet Olympiads. And by the end of the year, the Organizing Committee decides on awarding our branch an honorary title: "Winner of the Open International Student Internet Olympiad" with the possibility of placing on the website of the university a banner with the logo of the Internet Olympiad.

The analysis of the results of the Internet Olympiad (table 1) shows a trend of growth in both quantitative and qualitative indicators (Fig. 1). Compared to the start of the Internet Olympiad (2012), to date, quantitative characteristics have increased 3.3 times (from 83 participants to 274), there is also an annual increase in the quantitative component compared to the previous year: in 2013 - an increase of $31 \%$, in $2014-62 \%$, in $2015-17.5 \%$, and in $2018-86 \%$. The largest increase in 
the quantitative indicator was in 2018. Regarding the quality indicators, we observe their increase by $47.6 \%$ in 2018 compared to 2012 . It is also worth noting their annual positive increment: in $2013-14.3 \%$, in 2014 $4 \%$, in $2015-8 \%$, in $2016-7.4 \%$. Undoubtedly, an increase in quantitative and qualitative indicators indicates the emergence of students' interest, their motivation and activation of cognitive abilities, the manifestation of unique individual personal qualities, which result in the formation of systematic engineering thinking of a future technical specialist, brings up an active, enterprising professional who aspires to improve their cultural and professional level. The increase in performance is a powerful incentive for further education, the involvement of an increasing number of interested students to participate in subject Olympiads.

Table 2. Winners Gallery Open International Student Internet Olympiad

\begin{tabular}{|l|l|l|l|}
\hline Full name & Discipline & $\begin{array}{l}\text { Status, } \\
\text { prizetaker }\end{array}$ & Year \\
\hline Ashrapov T.R. & Physics & Bronze & 2013 \\
\hline Badretdinova A.I. & Ecology & Bronze & 2014 \\
\hline Bayazitova L.R. & Russian history & Bronze & 2013 \\
\hline Bayazitova L.R. & $\begin{array}{l}\text { Russian } \\
\text { language }\end{array}$ & Bronze & 2014 \\
\hline Vasikov T.E. & Russian history & Bronze & 2018 \\
\hline Gareeva K.F. & Chemistry & Bronze & 2016 \\
\hline $\begin{array}{l}\text { Dagirmanova } \\
\text { D.M. }\end{array}$ & Economy & Bronze & 2015 \\
\hline Teregulov R.A. & $\begin{array}{l}\text { Strength of } \\
\text { materials }\end{array}$ & Silver & 2017 \\
\hline Fazliev K.I. & $\begin{array}{l}\text { Russian } \\
\text { language }\end{array}$ & Silver & 2012 \\
\hline Fazliev K.I. & Physics & Silver & 2014 \\
\hline Fatkullin I.F. & Russian history & Bronze & 2013 \\
\hline Fatkullin I.N. & Russian history & Bronze & 2015 \\
\hline Fatkullin I.F. & Russian history & Silver & 2014 \\
\hline Khakimov I.I. & $\begin{array}{l}\text { Russian } \\
\text { language }\end{array}$ & Bronze & 2012 \\
\hline Chervyakov V.O. & $\begin{array}{l}\text { Russian } \\
\text { language }\end{array}$ & Bronze & 2012 \\
\hline Chervyakov V.O. & Physics & Bronze & 2014 \\
\hline
\end{tabular}

Proceeding from the gallery of prize-winners which is presented in table 2 , we see that in the period from 2012 to 2018 students became winners of Olympiads:

- bronze medalists in the following disciplines: ecology, chemistry, economy, twice in physics, four times in Russian language and Russian history;

- silver medalists in the disciplines: strength of materials, physics, ecology, Russian history.

These data demonstrate the intensification of the cognitive activity of students of a technical college through the individualization of training.

\section{Conclusion}

Analysis of the results of competitions in all academic disciplines allows to draw conclusions not only about quantitative and qualitative indicators, but also allows scientific advisers:

- manage cognitive activity;
- induce students to pursue focused, energetic learning;

- find more effective methods and means of teaching and preparing for subsequent Olympiads.

In the future, the faculty of the higher educational institution plans work on preparing students for Olympiads taking into account the analysis and adjustment of the results of the Olympiads held and reflects them on optional classes, in circles, on additional self-preparation of students. Thus, the versatile areas of extracurricular work are a complex, but the unified and well-coordinated mechanism of activity of the faculty and students, aimed at the formation of an intellectually developed and spiritually rich person. At the same time, the Olympiad movement provides substantial support in the development of a schoolchild's value and holistic outlook.

In conclusion, it is necessary to note that scientific research and methodological activities are an indispensable component of the work of the faculty of a higher educational institution. Exploring pedagogical phenomena, the teacher organizes not only his professional knowledge, forms his pedagogical style, his personal and professional worldview, but also activates the cognitive activity of students through the individualization of learning. It is advisable to start systematically scientific and methodical work on individualization of tasks as early as possible, to study the most urgent problems of preparing students for scientific research, to consider them from different positions and with different levels of study and as a result to take part in student Olympiads at various levels.

\section{References}

1. E.L. Guseinova, E.E. Guseinova, Organizational and pedagogical conditions for the development of professional competencies in the technical students' individual work through the example of studying the discipline "Hydraulics and fluid mechanics", European J. of Contemporary Ed., 7(1), 118-126 (2018)

2. A.Z. Ibatova, N.V. Ippolitova, S.K. Mukhametgaliyeva, A.E. Rodionova, K.N. Yagafarova, L.N. Ikonnikova, Lifelong professional education in the Russian federation: Personal aspect (research article, Scopus), Int. J. of Environmental and Sci. Ed., 11(16), 9426-9436 (2016)

3. R.R. Shangareev, Role of employee motivation in an industrial occupational risk management system, IOP Conf. Ser. Earth and Environmental Sci., 194(2), 1-7 (2018). Article number 022033

4. R.N. Yusupov, Resource of Russian religious and philosophical tradition in a constructive relationship with west, European Proc. of Social and Behavioural Sci. (RPTSS 2018 - Int. Conf. on Res. Paradigms Transformation in Social Sci.), 50, pp. 1402-1408 (2018). DOI: 10.15405/epsbs.2018.12.171

5. A. Mecke, I. Lee, J.R. Baker jr., M.M. Banaszak Holl, B.G. Orr, Eur. Phys. J. E 14, 7 (2004) 
6. E.A. Mukhtasarova, F.G. Safin, State of modern Russian youth toleranc[, European Proc. of Social and Behavioural Sci. (RPTSS 2018 - Int. Conf. on Res. Paradigms Transformation in Social Sci.), 50, pp. 206-213 (2018). DOI: 10.15405/epsbs.2018.12.26

7. Campbell James and Walberg Herbert Olympiad Studies: Competitions Provide Alternatives to Developing Talents That Serve National Interests, Roeper Review-A J. on Gifted Ed., 33,(1,SI), 8-17 (2010)

8. A. Domoshnitsky, V. Bugaenko, R. Yavich, Int. Mathematical Internet Olympiad IMSCI'11: The 5th Int. Multi-Conf. on Society, Cybernetics and Informatics, II, pp. 268-273 (2011)

9. S. Petersen, P. Wulff, The German Physics Olympiad-identifying and inspiring talents, European J. of Physics, 38(3), 034005 (2017)

10. M C. Pyrt, Talent development in science and technology, Int. HDB Giftedness T, 427-37 (2010)

11. H.W. Marsh, D. Chessor, R. Craven, L. Roche, The effects of gifted and talented programs on academic self-concept - the big fish strikes again, American Ed. Res. J., 32, 285-319 (1995) 